\title{
Meeting the test of future relevance ${ }^{1}$
}

\author{
by T.M. Apsey, R.P.F. ${ }^{2}$
}

Our 50th anniversary gives us much to celebrate, yet we are still a relatively young profession. Although we have made great strides in the past 50 years, as a profession the challenges and rewards of maturing lie mainly ahead of us. Measured by the human time frame, I believe our profession is on the verge of becoming a teenager.

For those of you who have parented the human variety of teenager, my analogy may be somewhat disquieting.

For those of you who have not yet had the experience of a home-grown revolution and evolution of spirit, thought and destiny, get ready for the ride of your professional lives. For, collectively as members, we are about to parent this profession through a great period of trials and tribulations, discovery and definition.

We are entering this phase of our profession at a time of great change in forestry in general. Over the next 50 years, the transformation of the province's commercial forests from natural to managed will be largely completed. Forests from many competing jurisdictions, as well as alternative raw materials and substitute finished products, will, to use a popular term, come on line more than ever before. Increasingly, information and technology will replace the natural resource as the most significant lever for competitive advantage. Relationships and responsibilities will change as international demands - whether through certification in the marketplace or through treaties between and among world governments — supplant the traditional dominance of the provincial government in setting regulatory framework in which the B.C. forest industry operates.

Although it must be a time of strengthening the public and private sector forestry partnership in British Columbia, there will be an increasing emphasis on private sector delivery and an increasing imperative that public policy be framed in a manner to allow that private delivery to occur. In short, while we are progressing through our own internal process of maturation, the forestry environment around us will also be changing markedly.

Throughout this era of flux, what will the industry be looking for from our profession? Simply, it will require foresters who can secure the right amount and the right kind of fibre supply at the right time and at the right cost.

Maybe that's not as simple as it sounds. Satisfying this demand would seem to call for a person with the combined qualities of Solomon, Martha Stewart and Mandrake the Magician. Or failing that, Mike Keenan. But, we should be under no illusion: our future, individually and collectively, depends on meeting this need. Of course, this is not the only need that will have to be met; far from it. But I am saying it is one that is critically important to the province, and therefore, it must be to us as well.

So that I am not misunderstood, satisfying this need is a challenge that must be met by our public sector members as well

\footnotetext{
${ }^{1}$ Paper presented to the 50th Annual General Meeting of the Association of British Columbia Professional Foresters, 6 March 1998, Victoria, BC.

${ }^{2}$ President and CEO, Council of Forest Industries of BC.
}

as our private sector members. We are in this together, and I am confident that, together, we can do the job.

To me, doing the job means meeting challenges on the individual level as well as on the level of the profession as a whole. Undoubtedly, the future will present many such challenges. Today, I'll touch on just one example at each level.

On the individual level, I see professional foresters becoming much more engaged in developing and implementing corporate strategies. They will be strategies designed to more closely match market opportunities to manufacturing capabilities and fibre availability. If you will, corporations will be more "holistic" in the strategies they follow from forest management to the marketplace. But they must also be more nimble and flexible, and this will require increasing involvement of foresters.

Again, let me emphasize that my references are not restricted to private sector foresters, but apply equally to the public sector foresters who I see charged with establishing a policy framework that recognizes and accommodates the needs of industry as well as satisfying other legitimate demands on the resource. Again, let's acknowledge that is no mean trick.

In this expanding role, industry will increasingly look to foresters for solutions to some very significant and potentially persistant problems. It's not that foresters today are not solution oriented, but our role seems sometimes limited to analyzing, implementing and just plain trying to cope with constraints on fibre supply.

If the B.C. industry is to survive and prosper in the tough competitive world down the road, it will not be on a declining fibre supply that carries some of the highest costs on the planet. Foresters have a great opportunity, and I think will be expected to proactively step forward, not merely to cope, but to overcome. Our critical focus must be on measures to return our fibre supply solidly to the asset side of the ledger, instead of hovering dangerously close to permanent residence on the liability side.

Although there is a particularly urgent need for these types of solutions in today's economic climate, the passing of the current crisis will herald not the end of the solution-oriented forester but merely the beginning. Such solutions are unlikely to lie in the forest alone but, rather, in the context of the holistic approach I have already mentioned. This means foresters must build their knowledge, talents and skills beyond the scientific areas that are the core of the profession. They must develop a much better understanding of markets and manufacturing and how fibre supply will be integrated into these rapidly and continually changing environments.

Although there will be increasing demand for specialization in the many disciplines of professional forestry, there will also be a very strong need for the generalist who understands the industrial enterprise from beginning to end and can make the sometimes seemingly disparate segments of forest, mill and market work together profitably. Perhaps this kind of forester, with skills and knowledge that I have just described, does not fit well within the traditional definition of the practice of professional forestry. If not, then perhaps our association is not yet pursuing a strategy that accommodates and provides for this kind 
of professional. The other panel members today may describe different kinds of foresters with other attributes that also depart from our more traditional concepts. If that is so, it may be a worthwhile exercise for our association, if it is not already doing so in the course of carrying out its strategic plan, to give some consideration to how these future foresters may be accounted for and supported within our membership and mandate.

The issue of mandate brings me to the point I want to make about a challenge to our profession as a whole. To state a simple law of economics, industry - any industry - uses inputs for one of two reasons. Either it is obligated to use a particular input because of law or other constraining factor, or it chooses to use one for the positive contribution it makes to producing a profitable output. Sometimes, both reasons prevail. In the case of our profession, the law currently requires that professional foresters be used for certain tasks, yet beyond the legal requirement professional foresters clearly provide excellent value to industry today.

We must not assume however, that today's statutorily protected mandate will, alone, continue to ensure our relevance for industry into the future. I'm not saying we should ignore, abandon or change that mandate. I am saying that, in the absence of a continuing and indisputable demonstration of underlying value of the inputs we provide, we may very well find that the mandate is eroded or even lost.

Let's make no mistake about it: society, the public, our clients are interested in results, not in maintaining a special status for any group of professionals if that does not serve those who have conferred that status. This is neither a new phenomenon, nor restricted to our profession. Where they fail to serve their purpose, government-created barriers to results, whether they be barriers to trade or mandates for professions, are falling. Ironically, it can be the very nature of the mandate as defined by statute, or as it is implemented, that undermines its value. As a profession, we need to ensure that the manner in which we are able to exercise our mandate serves, rather than hampers, the objectives for which that mandate was created.

Whether it is a case of institutionalized redundancy, where the work of some members is reviewed by others, or the inappropriate replacement of professional judgement by so-called cookbook regulations and standards, we must act as a profession to ensure that our mandate is preserved where it serves legitmate interests. It is equally important that we also ensure in those circumstances, that the mandate is applied in a manner that enhances the delivery of desired results. I believe our profession is taking important steps in this regard, but this is an ongoing challenge that will require our constant vigilance in the years ahead.

From an industry perspective, then, these are two challenges I see for professional foresters. For individual foresters, to make significantly greater contributions to strategic decisions that enhance industry competitiveness. For the profession as a whole, to preserve its statutory mandate by ensuring that mandate is constituted and applied in a manner that most effectively serves those who have conferred it.

I do not underestimate the significance of these and the many other challenges that will present themselves to our profession over the next 50 years. But I am unequivocal in my confidence and belief that all such challenges will be met - no, not just met, exceeded.

Let the fun begin! 